\title{
Chapter 1 \\ Advocating for linguistic equality
}

\begin{abstract}
Para mí es importantísimo difundirlo [zapoteco]. Pero siento que el gran error ha sido--- el gran error antes era enseñar español y se perdió el zapoteco. Y ahora el gran esfuerzo es rescatar el zapoteco. Pero el gran error está en querer forzar a las personas a hablar zapoteco. Ya no puedes recurrir a la barbarie de antes obviamente. Pero entonces ahora, ¿cómo le haces? Hasta que no crees una conciencia real en las personas, no va a haber eso.
\end{abstract}

For me it's extremely important to spread [Zapotec]. But I feel that the big mistake has been- The big mistake before was to teach Spanish, and Zapotec was lost. And now the big effort is to rescue Zapotec. But the big mistake is in wanting to force people to speak Zapotec. You can't return to the barbarity of before obviously. So now, how do you do it? Until you create a real awareness in people, it won't happen. ${ }^{1}$

(Mayoli García, Interview May 2014)

Language is one of the domains of social life where inequalities are pervasive; consequently, it is also a point of focus for those in pursuit of social justice and change. The kind of change which social actors envisage varies, however, and ideas about how positive change may be achieved are likewise diverse and sometimes in conflict. As the above comment by Mayoli García, ${ }^{2}$ a student of Isthmus Zapotec language in Oaxaca, Mexico, notes, the obligatory teaching of one language (in this case Spanish) led to the displacement of Indigenous languages of Mexico such as Zapotec. She argues that current efforts to achieve a more equal status for Zapotec should not follow the same forceful approach to changing language practices, but should rather focus on creating awareness about this issue. Her concern about how to be an effective advocate for Zapotec, creating a positive change in the unequal, minoritized status of the language and the people who speak it, is also the driving question of this book. How to bring about positive social change in relation to language? Who participates, what kinds of change do they imagine, and what actions do they take?

As conceptualized in this book, language activism is a social project that aims to counter language-related inequalities, and may encompass many different actors, imaginaries, and actions. I view various forms of activism, advocacy, promotion and stance-taking as part of the same larger political project to resist inequalities and/ or imagine new avenues towards linguistic equality. The social

1 All translations are mine. Please see appendix B on transcription, citation, and date conventions.

2 I use a mixture of pseudonyms and real names in this study, following individual preferences.

Ә Open Access. (c) 2021 Haley De Korne, published by De Gruyter. (c) BY-NC-ND This work is licensed under the Creative Commons Attribution-NonCommercial-NoDerivatives 4.0 International License.

https://doi.org/10.1515/9781501511561-001 
positioning of actors and the level and kind of activism they engage in vary widely; some social actors contributing to this project identify as language activists, advocates or promoters to various degrees, such as Mayoli. There are also many actors who identify neither as activists nor as language professionals, yet it is useful to consider their imaginaries and actions as part of this broader social domain, as will be examined in the chapters that follow. Language activism does not target language alone; rather its targets can include any of the many inequalities in which linguistic discrimination plays a role, including economic, political, gender, class and racialized forms of marginalization. The positioning of actors as members or non-members of minoritized language communities is complex, as is the positioning of actors as insiders or outsiders of certain social domains, such as public education. Rather than accept a simplifying distinction between community-insider activists and community-outsider advocates, or disruptive activists and system-internal advocates, I examine how actors participate in fluid forms of activism, advocacy, and language politics across multiple communities of practice. By adopting a broad understanding of language activism and advocacy in relation to who participates, the social coalitions that they participate in, and what actions can contribute to increasing linguistic equality, I aim to provide a fuller picture of the power dynamics of linguistic inequality and potential networks of support.

This book will tell the stories of a few of the language activists engaged in resisting the inequalities experienced by members of the Isthmus Zapotec language community. Isthmus Zapotec is an Indigenous language spoken primarily in the Isthmus of Tehuantepec, Oaxaca, Mexico, hereafter also referred to interchangeably by the auto-denomination Diidxazá and the common simplification Zapotec/Zapoteco. ${ }^{3}$ These stories provide insight into the imaginaries and strategies of language activism initiatives across several social domains, including academic research, public schooling, higher education, community education, and popular culture. Minority language activism can occur in many social domains and can be initiated from official political spaces, often called top-down initiatives, as well as personal, communal, and informal spaces, often called bottomup initiatives. This is not a smooth nor linear process; positive linguistic change

3 There are four branches of the Zapotec language family, with a debated number of language variants which are not mutually intelligible (Pérez Báez and Kaufman 2016). Many of these languages are locally called simply Zapoteco/ Zapotec. The terms Zapotec and Zapoteco in this book refer only to the Isthmus Zapotec variant; where other variants are mentioned this is explicitly indicated. At the time of writing this book there are on-going discussions about spelling norms for Isthmus Zapotec. I use the spelling 'Diidxazá', which is the spelling used by the 1956 popular alphabet and the accepted standard in use during my fieldwork. 
holds different meanings or imaginaries for different actors from local to global levels, and is often a topic of intense debate. This book focuses primarily on language activism and advocacy at the local level, drawing attention to how diverse social actors imagine and enact strategies which aim to contest linguistic inequalities in a specific place and time. Through ethnographic description and analysis of multiple language activism initiatives, I sketch a repertoire of language activism strategies and aim to provide greater understanding of language activism as a negotiated social project which may inform and encourage activists, scholars, and educators working for change in other contexts of linguistic diversity and inequality.

\subsection{Are all ways of communicating equal? Imaginaries of linguistic equality}

Diversity is an inherent feature of the phenomenon of language. The range of linguistic families in the world, numerous dialects and registers within each community, and the variation of communication practices among different actors and contexts, and over time, are all part of the immense variation within human communication (Blommaert 2010). The Isthmus Zapotec language is no exception, as a part of the larger Zapotec language family which contains extensive variation and is spoken alongside other Indigenous languages and Spanish in southern Mexico (Pérez Báez and Kaufman 2016). These different ways of communicating are considered to be of equal value by linguists, who point out that each social group achieves their communication needs through a unique combination of features, including linguistic features (such as sounds, structures, and styles) as well as visual features (such as gestures and images). Diverse ways of communicating are of equal social value in that they are equally capable of fulfilling communicative functions within their unique time and place.

The equality of communication practices from this scholarly perspective quickly shifts when viewed from a socially, historically, and politically specific perspective, however. Humans- from social groups and scholarly disciplines to institutions and governments- have created a variety of ways of categorizing and valuing different language practices, so that language diversity is not neutral in most interactions, but is often deployed in the creation of power and hierarchy. Inherent diversity in sound, style, and so forth, is used to create social distinction and often social hierarchies (Bourdieu 1984; Agha 2007). In this sense, minority language should not be understood as an objective label relating to a low number of speakers or reduced territory, but rather a socio-political condition defined by a lower or minoritized status relative to other languages 
and subject to constant negotiation and shift. As discussed further in chapter two, in the Isthmus of Tehuantepec, Indigenous language speakers are often considered to have a lower social status than speakers of Spanish, with Indigenous languages typically being referred to as dialectos, popularly understood to be a rudimentary form of speech which is lesser-than-language. Many Indigenous languages around the world have been minoritized through similar processes of colonization and discrimination. Likewise a (minoritized) speech community, as explored in this volume, is neither a fixed nor homogenous entity, but refers to a social group whose members engage in shared meaning-making practices. Rather than being separate and contained, language or speech communities are often understood and defined in relation to other groups (Morgan 2004). Hierarchies also exist within speech communities, often among speakers of different varieties, generations, genders or social classes. For example, young adult speakers of Isthmus Zapotec are sometimes mocked by older speakers, as discussed in chapter 5 . The social construction and negotiation of endangered or marginalized language communities is especially complex as these communities are often (re)defining themselves under conditions of discrimination and material inequality (Kroskrity 2014). Social difference and discrimination may be based on any feature of communication, and occur within as well as between speech communities.

This tendency to minoritize in contexts of language diversity has long posed a challenge for scholars and members of multilingual speech communities; as Haugen (1973) wrote, "language is not a problem unless it is used as a basis for discrimination, but it has in fact been so used as far back as we have records" (54). The role that language plays in the creation and reinforcement of social inequality may be subtle and overlooked, yet can lead to important social consequences. Within educational contexts, children from minoritized speech communities are often disadvantaged and evaluated poorly on the basis of their linguistic abilities, regardless of their content knowledge and general capacities (Heller and MartinJones 2001). Many residents of the Isthmus of Tehuantepec, or Istmeños, recount their negative experiences being punished and silenced in Spanish-only schooling (see chapters 2 and 4). The impacts of linguistic inequality are felt in many other areas of social life as well, from the legal and health systems to the employment market. With this in mind, Ingrid Piller has argued that "addressing linguistic disadvantage must be a central facet of the social justice agenda of our time” (2016: 6).

The notion that humans should not be disadvantaged on the basis of the language or dialect they speak was part of the broader ideology of human rights which received widespread acknowledgement in certain social and political circles following World War II. An influential position paper published by the 
education branch of the United Nations, UNESCO, in 1953, promoted the use of vernacular or mother-tongue education for children from minoritized communities, contrasting with the prevalent trend of educating children in majority, national languages only (UNESCO 1953). This position has been reinforced through numerous other declarations and policies at international and national levels, such as the UN Declaration on the Rights of Indigenous Peoples (United Nations 2007) and the Mexican national Law on the Linguistic Rights of Indigenous People (Ley General de Derechos Lingüísticos de Los Pueblos Indígenas 2003). Linguistic rights have become closely intertwined with discourses and initiatives promoting human rights and social justice in many parts of the world (Skutnabb-Kangas and Phillipson 1994). New forms of language activism on the international scale continue to emerge, such as the UN declaring 2019 as the year of Indigenous languages. ${ }^{4}$

Linguistic equality has therefore come to be an established ideal in many social domains, in addition to being a fundamental notion within linguistic science, although it is far from being achieved in social relations. In this sense, linguistic equality is a social imaginary rather than a social reality. The fact that numerous people share an orientation in favor of a pluralist (and plurilingual) way of life is evidence of what Charles Taylor (2002, 2004) describes as 'modern social imaginaries', expanding Anderson's (1991) imagined communities beyond a nation-state frame. Taylor (2002) describes the social imaginary as "the ways in which people imagine their social existence, how they fit together with others, how things go on between them and their fellows, the expectations that are normally met, and the deeper normative notions and images that underlie these expectations" (106). He discusses how normative social imaginaries shift over time, noting that notions of equality and mutual benevolence among individuals (including inherent human rights) have developed through a "long march" from governance by naturalized hierarchy towards the social imaginary of shared democratic control, a transition which is not complete. I situate the social project of contesting language inequalities within this overarching social imaginary, which projects a specific "moral order of society" (Taylor 2002: 92) in which all voices deserve equal value. Like human rights, linguistic equality is an imaginary which often remains a struggle to uphold in social practice due to conflicting norms and politico-economic structures which promote the wellbeing of some over that of others.

The variety of perspectives and beliefs held by different social actors in relation to language has been explored in the study of language ideologies, or

4 https://en.iyil2019.org/ 
"the understandings, beliefs, and expectations that influence all choices made by language users ... [and] speakers' sometimes-idealized evaluations and judgments of appropriate language forms" (McGroarty 2010:3). Complex and conflicting ideologies have been described in Indigenous language contexts in Mexico, where expectations of purism, tradition, adaptation and change overlap and clash (Hill and Hill 1986; Messing 2007). Kroskrity (2018) argues that although language ideologies have been studied individually, they usually exist in complex constellations which he terms 'language ideological assemblages' (Kroskrity 2018). Conflicting ideologies within a language activism initiative can prove challenging for those involved (Kroskrity and Field 2009; Kroskrity 2009), yet this multiplicity is largely inevitable, and worthy of consideration in and of itself. I view ideologies and imaginaries similarly, noting that diverse actors in the Isthmus hold different views of what is positive or desirable, and negative or undesirable in relation to the changing communication practices around them.

Further, a variety of discourses, or "particular ways of representing part of the world" (Fairclough 2003: 26) (see also Foucault 1980), contribute to strengthening or weakening different ideological positions. For example, a discourse that represents Indigenous Oaxacan languages as valuable and of equal status with Spanish, such as the Todos se llaman lenguas [They're all called languages] campaign, by the non-profit cultural center Centro Académico y Cultural San Pablo in Oaxaca City, is informed by and contributes to the imaginary of linguistic equality, while resisting language hierarchies. The discourses produced by the campaign through flyers and on-line publicity ${ }^{5}$ reinforce and re-create this imaginary, attempting to spread it among members of the public. This imaginary also helps to motivate the Centro Académico y Cultural San Pablo to undertake practices which promote Indigenous languages in academic spheres, including hosting a bi-annual conference on Oto-manguean languages (the language family within which Zapotec is classified) and maintaining a large collection of Indigenous language books (among other languages and topics). ${ }^{6}$ At the same time, the fact that many people refer to Indigenous languages as dialectos, not as languages, shows that the colonial-era ideology which places Spanish above all Indigenous forms of communication is widespread and present in daily discourses. The language ideological assemblage in Oaxaca thus includes imaginaries of linguistic equality, and on-going ideologies of linguistic inferiority.

5 Promotional video: https://www.youtube.com/watch?v=0Vck43KLPKc. Original campaign website: www.todas-lenguas.mx

6 http://bibliotecajuandecordova.mx 
To claim that linguistic equality is a social imaginary is not to claim that it is a unanimously accepted norm, nor that all members of society embrace or pursue this imaginary in the same way. While arguing that linguistic equality represents a wide-spread ideal or imaginary around the world in the twentyfirst century, I also note that there are different notions of what linguistic equality is in practice, and different notions of how it should be achieved. For some, the inequality experienced by Indigenous language speakers in Mexico is best addressed by imposing the use of Spanish in all contexts, so that equality is understood as a forced homogeneity. For others, equality is best addressed through changing social norms and services so that speakers of diverse languages will have equal access and opportunities while using their own language. These differences in ideologies surrounding Isthmus Zapotec and other minoritized languages contribute to the tense politics of language activism. In education contexts where choices about which languages and which linguistic varieties to teach must be made within the constraints of time and resources, there are often fraught considerations over what will contribute to social wellbeing and long-term equality for students. Understanding the imaginaries present in a specific context is a crucial first step towards ascertaining how these imaginaries might be advocated for and eventually brought closer to reality.

\subsection{Advocating for what? Approaches to 'language'}

Among the social actors who espouse imaginaries of linguistic equality, there is a great deal of variation in what is understood by 'language'. Perspectives or ideologies of language may be painted in broad brush strokes as ranging from viewing language as an object to viewing language as a social practice. The view that language is an object that can be considered autonomous from context is wellestablished within linguistics, where structuralist and positivist approaches to language have enjoyed considerable attention and prestige. Linguistic scholarship remains influenced by Saussures's langue/ parole and Chomsky's (1965) competence/performance dichotomies, both of which give higher status to the study of langue, competence, and linguistic form. The desire to standardize linguistic practices to conform to an idealized target or native speaker has motivated much applied linguistics scholarship, and in turn influenced many language classrooms. Although there are discussions about the need to go beyond simplistic notions of mother tongues and native speaker competence (Firth and Wagner 1997; Larsen-Freeman and Cameron 2008), these essentialist notions remain commonplace in much language education practice. Autonomous, objectified views of language have thus been taken up among actors outside of the ivory tower, in 
particular through schooling. Promoting an essentialized link between a (standard) language, a culture, and an identity has been a strategy of control among the founders of nation-states, in particular in Europe (Gal 2006). Political rhetoric, and language and education policy, continue to create a monolingual and monocultural norm in many parts of the world (Tollefson 1991; Piller 2016).

Heller (2007) discusses how research in the field of bilingualism has helped deconstruct autonomous notions of language, as well as static views of identity, culture and community. She argues for a shift "away from the whole bounded units of code and community, and towards a more processural and materialist approach which privileges language as social practice, speakers as social actors and boundaries as products of social action" (1). A social practice approach views language as something that is created within and by a specific sociocultural context, and that simultaneously impacts and shapes its context of use (Goffman 1981; Bakhtin 1986; Bhabha 1994; Makoni and Pennycook 2007). I refer to this perspective on language and community as constructivist, using this as an umbrella term for the constellation of perspectives that focus on context, process, and the co-construction of both language and social groups.

Constructivist perspectives on language have led to the promotion of integrated and fluid language use in multilingual contexts, building from additive bilingualism (Lambert 1975) towards flexible multilingualism (Blackledge and Creese 2010) and translanguaging (Williams 1994; García 2009a). These integrated approaches to multilingualism stand in contrast to 'parallel monolingualism', the ideology that multilinguals should use each language autonomously, rather than mixing and overlapping (Heller 1999). On a larger social scale, a constructivist perspective attends to the linguistic ecologies that emerge through interaction and contact among language communities, creating flows of influence and exchange, especially in multilingual territories (Haugen 1972; Fill and Muhlhausler 2001; Maffi 2001). Power and influence among speakers and speech communities is not understood as top-down nor unilateral, but rather as a dynamic relationship in constant negotiation as a result of numerous contextual factors from local to global scales (Ricento and Hornberger 1996; Hornberger and Hult 2008). Additionally social perspectives on language typically claim criticality, examining power relations and inequalities that may be established and perpetuated through language practices (Bourdieu 1991; Heller and Martin-Jones 2001; Pennycook 2001).

Social practice or constructivist perspectives on language are also reproduced within certain strands of education and popular culture that embrace the fluidity and co-construction of knowledge and meaning. For some educators language learning is understood as a social process that is co-constructed between the learner and those around them, rather than a linear trajectory towards a 
target norm. The learning process involves building on all available "funds of knowledge" (Moll et al. 1992) in order to develop a contextually appropriate communicative repertoire (Gumperz 1968; Rymes 2010) or a shared repertoire (Wenger 1998) that allows the learner to engage in a community. Recognizing the differing literacy and oral language use patterns of cultural groups, such as Native Americans in contrast to European Americans (Philips 1972; Street 1984; Eriks-Brophy and Crago 1994), is a result of constructivist ideologies of language and literacy. Furthermore, educators may confront inequalities which result from these differences through culturally responsive and sustaining pedagogy (Ladson-Billings 1995; Paris and Alim 2017). Writers, musicians and artists in minoritized communities also often align with a social perspective on meaning-making, contributing to discussions and discourses about fluid forms of language and culture in more or less explicit ways (Webster 2010; Moriarty and Pietikäinen 2011; Williams and Stroud 2013).

Such perspectives are often articulated against a variety of autonomous and essentializing views of language promoted in formal education, politics and the media, whereby a language is seen as autonomous, fixed, and governed by rules to which users must adhere, and is often closely fused with a place and a national identity (Makoni and Pennycook 2007; Blommaert 2010). The political discourse that all Mexicans should speak standard Spanish in order to preserve national unity and because it is superior to Indigenous ways of communicating, is an essentialist language ideology that promotes a homogenous and Eurocentric language ecology. Indigenous, minority languages in particular are often presented in simplistic or essentialized ways in the media and in some scholarly discourses; as exotic structures for linguists, as countable, diminishing resources, or as the channel to an authentic culture and place (Muehlmann 2008, 2012; Moore, Pietikainen, and Blommaert 2010). Many of these representations take place amidst discussions about the marginalization or decline in use of Indigenous languages around the world, generally called language endangerment (Hale et al. 1992). In the media, Indigenous languages of Mexico are often discussed as 'lenguas en riesgo', languages at risk, and described as an authentic form of identity or a treasure that is - sometimes 'unfortunately', sometimes 'inevitably' - being lost. The discourses used to describe and draw attention to language endangerment may contribute to the ideology of language as an autonomous object, and an essentialized link to identity (Hill 2002).

The ideologies or perspectives of actors who advocate for a response to language endangerment are diverse, falling all along the continuum from autonomous to constructivist perspectives and exhibiting varying expectations and beliefs about Indigenous language use across social domains. For example, 
actors holding an objectifying view of language may feel that linguistic equality has been achieved when all languages are documented and archived, thus preserving them with some degree of accessibility for future generations. On the other hand, actors with a more constructivist perspective may feel that the creation of contexts for language use are essential for all language communities to experience equality, resulting in initiatives such as language nests and immersion schools (Kamanā and Wilson 2001; Hinton 2013). Indigenous language speakers and activists have long emphasized social and material understandings of language, as a form of identity, spirituality, connection to land, and relationality to the collective (Ferguson 2010; Meek 2010; Hermes, Bang, and Marin 2012). Henne-Ochoa et al. (2020) discuss Indigenous conceptions of "language-as-a-process-of-sustaining-relationality" (483) with a community and with a place. They note the crucial links between language, place, and identity, while highlighting that it is not a linguistic object that makes these links but rather communication as social action and as process. Consequently, they argue for an approach to language reclamation centered around social relations.

Constructivist and essentialist understandings of language are not necessarily opposed. Many would argue justifiably that language is both an object and an action. When limited resources and time are available for advocacy initiatives, however, one view may come to dominate the other, and efforts may be channeled one way over the other. Should funding and the limited time of Indigenous language speakers be devoted to the production of a dictionary or to a weekend class for children? Who gets to define what language is, and how it is represented, is a crucial concern. Myaamia linguist-activist Wesley Leonard argues that the definitions of linguists and others who have often claimed epistemological authority must not be taken uncritically; rather the definition of 'language' must be decolonized so that the understandings and priorities of Indigenous speakers and community members guide Indigenous language initiatives (2017). At the same time, Leonard and others acknowledge that there are likely to be multiple definitions and understandings of 'language' within a community (Messing 2007; Kroskrity 2009; McKenzie 2020), necessitating an open approach to the question 'what is language?'

With this in mind, my conceptualization of language is fundamentally constructivist and social as I seek to illuminate the relationship of communication practices and social well-being - language and inequalities. As Pennycook (2010) articulates it, "To look at language as a practice is to view language as an activity rather than a structure, as something we do rather than a system we draw on, as a material part of social and cultural life rather than an abstract entity" (2). However, I regularly participate in essentialist language discourses as 
I interact with different disciplines and actors and engage in various aspects of language education. This is common of many social actors, who may understand language in multiple ways, and develop their priorities for language activism accordingly. All of the ways that different actors perceive and consequently engage with minoritized Indigenous languages are a central concern of this volume, in particular when these forms of engagement become institutionalized and codified within political systems, social projects and intellectual disciplines.

\subsection{Advocating how? Approaches to equality and social change}

Different actors aim to rectify inequalities experienced by minoritized language speakers in diverse and sometimes conflicting ways, ranging from promoting linguistic homogeneity to promoting equal status for diverse languages. If everyone speaks the same language, this might be considered equity - the same resources given to all. Equality or justice, however, is not so context-independent, and must be considered in relation to the experiences and opportunities of social actors in situ. Just as it is important to grasp the multiple ways that language is understood and made meaningful in human life, so it is equally important to be aware that equality, justice and positive social change mean different things to different people. There are complex ideological assemblages and shifting material conditions which inform peoples' understandings and priorities of what change should occur. For parents in the Isthmus of Tehuantepec it is generally viewed as a positive change that children are growing up as confident speakers of Spanish, a capacity that will allow them more social opportunity and equality in present-day Mexican society. At the same time, some parents also lament that many children are not confident speakers of Diidxazá, while young adults express regret that they are not able to communicate with their grandparents as comfortably as they would like. From a linguistic perspective, speaking Spanish and Diidxazá do not need to be opposed, and yet in the current social context one is often viewed as a detriment to the other.

Minority language activism can thus have many goals: advocating for the rights and opportunities of members of minoritized communities (including the right to learn socially-powerful languages), revitalizing endangered languages, and promoting Indigenous language education, among others. As stated in section 1, I also define the practice of activism in a broad and flexible way, including strategic actions by insiders and outsiders, as well as stance-taking in relation to social issues. In the pages that follow, some of the diverse imaginaries and strategies within the domain of minority language activism will be illustrated 
through cases of language activists in Oaxaca. My goal is to present language activism as a social domain with inherent internal diversity, where different understandings of positive social change and the subjective nature of equality need to be taken seriously. This diversity can sometimes result in conflict and disagreement about the goals, processes and outcomes of initiatives; however, it can also lead to new insights when language activists are aware of this diversity and find ways to work with it.

Taking action while adhering to a constructivist paradigm is not straightforward, due to acknowledgement of the validity of multiple points of view, and the inability of any individual to consider a context in its entirety. This predicament has been considered by numerous scholars, who question whether and how to take action and avoid a postmodern paralysis when multiple approaches are considered valid. Although a post-modern or constructivist approach embraces the deconstruction of social categories, including right and wrong, a relativized morality can still be established within individual contexts. Pennycook (2006) advises that post-modern activists should attempt to address difference, dominion, disparity and desire among stakeholders, while Janks (2000) proposes attention to diversity, domination, access and design. Attending to and addressing forms of inequality are key in both of these approaches. Action research practitioners Greenwood and Levin (1998) argue for a "pragmatic" approach, informed by "a strong commitment to the democratization of knowledge, learning, and selfmanaged social change" (10-11). As scholar-activists they do not aim to guide or impose change, but are "participants in change processes where democratic rules guide decision making" (11). A pragmatist paradigm such as this edges closer to the possibility of objectivity via democratic consensus, and as such may be preferred by some activists. A constructivist or post-modern paradigm will generally require a willingness to repeatedly question and deconstruct one's own assumptions, including assumptions about what constitutes knowledge, learning, and participation. Both constructivist and pragmatist or democratic approaches offer the possiblity to avoid essentialist or positivist paradigms while engaging in social change.

In contrast, there are many approaches to achieving language equality which have not adopted a constructivist nor pragmatist perspective. Official approaches to linguistic equality have consisted of policies at international and national levels, often drawing on an objectifying or essentialist paradigm of language. Language has come to be viewed as part of broader human rights, as mentioned above, and United Nations declarations such as the Declaration on the Rights of the Child (1959) and the Declaration on the Rights of Indigenous Peoples (2007) have created rhetorical support for language activism in national and local spheres. The recognition of linguistic human rights has not 
lead to the establishment of linguistic equality in practice however, leading to arguments that top-down solutions are insufficient (Stroud and Heugh 2004; Lim, Stroud, and Wee 2018). As Wee (2018) argues, "Neither groups and their members nor their cultural practices are ontologically fixed and homogenous entities, though a rights discourse treats them as such" (53). He points out that an essentialist approach to language rights runs the risk of defining language and community in a narrow way, and creating new exclusions. At the same time, the collective, communal nature of language use, and the co-substantiation of language and identity have been emphasized by many Indigenous language activists, as discussed above, lending weight to arguments for collective rights. Declarations of linguistic rights on international and national levels have offered a path towards some improvements, even if they continue to fall short in practice (Skutnabb-Kangas 2018).

In line with the critiques leveled at linguistic rights, scholars' attempts to support marginalized groups have similarly been taken to task for leading to disappointing results, in particular when they draw on a positivist discourse of correcting the misinformation and 'myths' about language(s). Lewis (2018) discusses the limitations of 'error correction', or the attempt to prove that a form of communicating that is widely viewed to be inferior is in fact equally complex and as efficient as more respected forms of communication. He points out that although sociolinguist William Labov famously illustrated the equality of Black English in both research and in a high-profile court case, this has not eradicated widespread prejudices against speakers of Black English. This further highlights the need to go beyond legal and academic declarations of equality. Scholars have often engaged in what Chickasaw anthropologist-linguist-activist Jenny Davis calls "linguistic extraction" or "defining, analysing, and representing languages and the people connected to them separately from the complex socio-historical, political, and deeply personal contexts in which they actually occur" (Davis 2017: 40). She argues that this practice distracts from sociohistorical and material inequalities, and distances speakers from authority over their own ways of speaking. The political and material conditions which serve to perpetuate linguistic inequalities also need to be challenged by scholaractivists in order to bring about positive change (Flores and Chaparro 2018). As Tuck and Yang (2012) point out, efforts to change or 'decolonize' perspectives and ideologies, while laudable, are not the same as actually changing power structures and access to resources.

Investigation into language and education policies at national levels has highlighted the key role of local actors in interpreting and putting policies into practice (Ricento and Hornberger 1996; Canagarajah 2005; Menken and García 2010). Sociolinguists also argue that we are increasingly in a post-national era 
(Blommaert 2010; Heller 2011), and as such it is appropriate that the strategies of engaged political actors orient to units of social organization other than the state, as well as to discourses and influences that circulate across social scales. Language and education scholar Christopher Stroud has argued that not only do local actors play a role in language politics, but that positive social change is more likely to occur through actions of bottom-up 'linguistic citizenship' than through top-down linguistic human rights. He notes that linguistic human rights "tends toward a privileging of official values and perceptions of what might constitute the language in question, and can only entertain the legitimacy of alternative language practices as part of the 'language' with difficulty" (Stroud 2018: 7). In contrast, he focuses on linguistic citizenship, or "what people do with and around language(s) in order to position themselves agentively, and to craft new, emergent subjectivities of political speakerhood, often outside of those prescribed or legitimated in institutional frameworks of the state" (2018: 5). When intended to confront linguistic inequalities (as is often the case in the examples explored by Stroud), these acts of linguistic citizenship are synonymous with language activism; conversely, all forms of language activism can also be viewed as linguistic citizenship. Along with Stroud and other ethnographers of language policy, I maintain that these individuals have significant power in language politics (Hornberger and Johnson 2007; Hult 2010).

Minority language activists, as conceptualized and explored in this book, are engaging in diverse acts of linguistic citizenship. Importantly, however, they are engaging not just as individuals, but also as parts of networks, communities or social projects. Social groups are significant contexts of socialization and thus also key sites for the negotiation of social change. Taylor (2002) suggests that "what start off as theories held by a few people may come to infiltrate the social imaginary, first that of elites perhaps, and then that of society as a whole" (106). When we consider linguistic citizens or language activists as parts of groups, we can better understand how their "emergent subjectivities of political speakerhood" (Stroud 2018: 5) may come to gain wider traction and bring about ripples of change - and certainly not only from a so-called 'elite' source as Taylor suggests. Organized forms of activism which build into social movements have played a significant role in political life in Latin America in particular, and are more likely to bring about social change than individual, indirect actions (Escobar and Alvarez 1992). While the goals and actions of those who identify as activists and engage in stereotypical efforts such as public demonstrations and targeted outreach are an important part of language activism (and are most likely what is readily conjured to mind by the term), I am also interested in quieter voices and subtler actions, including certain choices and stances which reach outward only in indirect ways, yet which also contribute 
to this domain. In this way, I locate language activism as part of language politics more broadly, and recognize that all social actors play a role in creating this political space (Canagarajah 2005; Davis and Phyak 2017).

One framework for examining collaborative social change is Jean Lave and Etienne Wenger's (1991; Wenger, 1998) theory of learning through which individuals are socialized into specific ideologies as well as communicative norms through participation in a community of practice. Communities of practice are characterized by shared discourses, goals, and collaboration. Literacy scholars David Barton and Karin Tusting (2005) have pointed out the crucial impact of context-specific communication norms and power dynamics within communities of practice, providing further nuance to this framework. Whether the community of practice shares an ideology that is accepting of language diversity and speaker agency, or views other communities' norms as inferior, or something in-between, it has a significant impact on the perceptions and practices of its members. For example Mayoli, the Zapotec student quoted in the introduction to this chapter, expresses her desire for the current community of people promoting the use of Zapotec to avoid taking up the same ideologies through which Spanish was promoted in the past, noting that they were barbarous and forceful; "el gran error está en querer forzar a las personas a hablar zapoteco. Ya no puedes recurrir a la barbarie de antes" [the big mistake is in wanting to force people to speak Zapotec. You can't return to the barbarity of before] she warns. As Wenger (2000) comments, "Communities of practice cannot be romanticized. They are born of learning, but they can also learn not to learn. They are cradles of the human spirit, but they can also be its cages. After all, witch-hunts were also community practices" (230).

The socialization that occurs within a community of practice can build towards greater linguistic agency, democracy and equality- or the opposite. Likewise, minority language activism can inadvertently lead to new forms of marginalization and disempowerment in the effort to change existing power relations (Cameron 2007; Leonard 2012). Numerous Indigenous language activists have argued the need for self-determination and local control in language advocacy initiatives as a way of avoiding imposed language ideologies and potential exclusionary outcomes (Leonard 2017; Hermes and Engman 2017; Henne-Ochoa et al. 2020). Similarly, social theorist Ivan Illich argued that top-down manipulation is the factor which undermines the potential of social institutions as sites of learning and well-being, while conviviality is the factor which, he proposes, supports and enables this potential (Illich 1970). He analyzes social institutions on a scale from manipulative to convivial, with the latter being his ideal social learning environment. Dynamics of manipulation and conviviality provide a useful analytic lens through which to consider participation in language activism initiatives, 
as illustrated further throughout the volume. Language activism initiatives can be viewed as communities of practice, each with their own internallynegotiated norms, goals, and dynamics of participation.

Additionally, the socio-political-historic context in which the community operates, and to which it must respond, is also significant. I examine language advocacy initiatives as socio-historically located communities of practice or social projects, following anthropologist Elizabeth Povinelli (2011). Povinelli describes a social project as "a metadiscourse that aggregates aspects of the social world" (11), and a space for social change similar to "counterpublics" (Fraser 1992; Warner 2002). Povinelli notes that social projects "extend beyond simple human sociality or human beings. [. . .] a social project is dependent on a host of interlocking concepts, materials, and forces that include human and nonhuman agencies and organisms" (7). The specific social projects that interest her are "spaces of otherwise" such as Aboriginal Australian ways of being, and how these can "endure" in hostile environments (29). Current social projects and imaginaries in favor of Diidxazá use emerge from and contend with contexts characterized by the presence of colonialism, nationalism, economic inequality and universalized formal schooling. The social project of colonialism in Mexico and elsewhere in the world created enduring linguistic and racial hierarchies, or forms of coloniality where Eurocentric logics dominate (Quijano 2000). The post-colonial projects of nationalist assimilation followed by neoliberal cultural recognition shifted public discourses about Indigenous languages to some degree, although the hierarchies remain largely intact with obligatory Spanish schooling playing an important role (as discussed further in chapter 2).

Against the bleak post-colonial and settler-colonial setting, Povinelli singles out social projects (separate from smaller "individuated projects" and larger "social worlds") as spaces of potentiality for new ways of being. She asks "How do new forms of social life maintain the force of existing in specific social spacings of life?” (Povinelli 2011: 9). In other words, how does a non-imposed, nonhierarchical Diidxazá speech community develop in today's post-colonial, neoliberal Mexico? As Mayoli goes on to ask, after rejecting forceful approaches to language promotion, "entonces ahora, ¿cómo le haces? Hasta que no crees una conciencia real en las personas, no va a haber eso" [So now, how do you do it? Until you create a real awareness in people, it won't happen]. Understanding language activism and potential social change requires attention to conciencia and the subjectivities of linguistic citizens; it also requires attention to the socialization and negotiation of power dynamics within communities of practice; and it requires consideration of the historical and material conditions in which these communities pursue their social projects. Social change can occur through official processes, such as policy declarations and curriculum reform, as well as 
through personal and social group practices, such as how a teacher chooses to interpret the curriculum and how students ultimately engage with it. Changing the unequal social realities experienced by Zapotec and other Indigenous communities is indeed a project in need of "new social imaginaries", new potentiality, the ability to think and behave "otherwise", as explored by Povinelli (2011) and Taylor (2004). So now, how are minority language activists doing it?

\subsection{A repertoire of activism strategies}

There are numerous ways that stakeholders in the Isthmus are working to counteract the processes of denigration that have linked local ways of speaking and being with poverty and ignorance, and excluded them from prestigious spaces such as education. Between 2013 and 2018 I observed many different practices related to the teaching, learning and promotion of Diidxazá, and engaged in some activism practices as an educator, linguist and researcher within a methodological framework of ethnographic monitoring (Hornberger 2013b; De Korne and Hornberger 2017). The socio-historic context of my observations is examined in chapter 2, and further methodological details are discussed in relation to academic research as a domain of activism in chapter 3. My research was guided by several questions: Who is engaging in language activism in the Isthmus, in particular in relation to Isthmus Zapotec? What imaginaries of language and social change do they express? What are their strategies of engagement? I noted that communities of educators, families, writers, artists, scholars, civil society organizations, missionaries, politicians and more were engaging in Diidxazá advocacy in some way. Taylor (2002) discusses the "repertory" of political actions that different societies exhibit, from organized protest to democratic elections. In line with a constructivist perspective of language politics, I consider the range of language activism practices in the Isthmus to constitute a repertoire of language activism strategies.

I also observed how language activists' social projects encompass various conceptions of Diidxazá and of positive social change. The different understandings of Diidxazá among the communities of practice that I consider range from a conceptualization of language as an object (among descriptive linguists for example), to a socio-political practice (among literacy advocates for example), to mobile symbolic capital (among some educated youth for example), and many others. My use of the term Diidxazá activism includes this understanding of the multiplicity of meanings that are attached to Diidxazá, without intending to reinforce any one meaning. Diidxazá activism is thus not a homogenous nor teleological social project; it is motivated by valorization of objectified 
languages, by certain social ways of being, by global opportunities, and by other desires associated with Diidxazá, and does not project a unified outcome. I explore this issue further in chapters 3 and 8 where I summarize the deictic and indexical nature of 'Diidxazá'. Recognizing that what is viewed as success or improvement will vary from community to community, and context to context, necessitates a post-structuralist or constructivist approach to activism. This is in line with scholars who have signaled the primacy of "community", "local", or "speaker" choices in endangered language initiatives (Cameron et al. 1992; Hornberger and King 1996; Czaykowska-Higgins 2009; Leonard and Haynes 2010), urging that choices about language be made by community actors so that it is their imaginary of positive change which guides action. Adopting a constructivist conception of activism also addresses the fact that multiple imaginaries can exist within communities, and that multiple choices may be viewed as legitimate.

Not surprisingly, Diidxazá language activists also engage in a wide range of strategies in pursuit of their varying imaginaries. While many of the activism strategies that are taken up in the pages that follow do not conform to stereotypes of loud, public, targeted activism, they do incorporate a fundamental degree of intentionality which sets them apart from social practices which are not strategic. Practices may reproduce or challenge structures of inequality in ways that are not intentional. Strategies, on the other hand, are practices which orient to an imaginary of social change and are carried out with the intention to influence social life in some way, large or small. As Wenger (1998) discusses, social and personal imagination may "conceive of new developments, explore alternatives, and envision possible futures”, but alignment of imagination with action or engagement is necessary in order to bring about change (178-180). Intentional or reflective forms of engagement are a distinct form of social practice in that they involve some degree of conscious choice, a dialogic relationship between reflection and action constituting what educational and social theorist Paolo Freire termed praxis (Freire 1969, 1970). Language activism strategies can be intentional in subtle and private ways, such as a grandparent's choice of language when interacting with their grandchild. They can also be intentional is more stereotypical ways, such as a teacher organizing public events in support of Diidxazá. Whether in public or private spaces, intentional strategies are a form of political participation and linguistic citizenship. The range of strategic practices exemplified by these actors constitute a repertoire of potential language activism strategies, as illustrated further below. I observed and compared the strategies of diverse actors in part to inform my own strategies as a language activist; with time and analysis these observations informed the 
following attempt to sketch out some of the local politics of Isthmus Zapotec activism and language activism more broadly.

Through analysis of my ethnographic data I developed a framework to categorize the strategic practices that I observed and participated in across local advocacy initiatives. The aim of this framework is descriptive; it is neither prescriptive nor comprehensive. Any and all strategies can be of use (or not), depending on the unique features of each context. There is no magic cure, no universal best strategy, no 'good' or 'bad' activism. The framework is sketched out starkly here and examples that fill out each aspect of it are presented throughout subsequent chapters. ${ }^{7}$ I organize strategies in terms of 1) a fundamental action; 2) the target of the action; and 3) significant characteristics of the strategy. The fundamental actions are forms of representing (representing something through discursive means), connecting (creating a connection among existing people, things, or spaces), and/ or creating (producing something new). These actions are most saliently targeted at the goals of resources, events, spaces or structures, people or identities, and communication practices, as represented in Figure 1.

\begin{tabular}{ll}
\hline Actions & Goals \\
\hline- Creating & - Resources \\
- Connecting & - Events \\
- Representing & - Spaces/Structures \\
& - People/Identities \\
& - Communication practices \\
\hline
\end{tabular}

Figure 1: Actions and goals of language activism strategies.

Resources refers to non-human materials, such as texts, recordings, videos, or other scholastic or educational products. Events refers to limited-term or oneoff occurrences that bring people together, such as a conference on Indigenous languages, a bilingual hip-hop concert, or a linguistic workshop. Spaces and structures refers to more durable social spaces such as schools or long-term education programs, including cultural centers and organizations. A one-time event may eventually become a space or structure if it reoccurs regularly. People and identities refers to people in their potential social roles as speakers, teachers, learners, experts, etc. Communication practices refers to any communicative practice, including all forms of reception and production, whether written, visual, or audio, mediated or face to face. A strategy may involve primarily one action and

7 A succinct representation of the framework is presented in Appendix A. 
one goal (such as the creation of didactic resources), however there are often multiple actions and goals overlapping and pursued simultaneously (such as the creation of successful learners and increased communication practices in the target language through the use of the didactic resources) as illustrated in the pages that follow. In chapters 3-7 I offer examples of these strategies in diverse activism initiatives, and discuss further aspects of the imaginaries and strategies of language equality in practice. While some strategies are driven by resistance to aspects of existing conditions, at the same time they are almost always also a form of reimaging conditions or imagining new realities, as explored in chapters 6 and 7 in particular.

In addition to these core actions and goals (the what of language activism strategies) there are several common characteristics which shape how strategies are carried out. These characteristics are represented as scales in Figure 2. The location or geographic affiliation of the people or actions involved may range from local to regional, national, and international. The timeframe within which a strategy takes place and reverberates can vary from a momentary choice, such as an individual choosing to post on social media in Zapotec rather than Spanish, to medium term and long-term endeavors, such as creating an app for language learning which will be used for a few years or a new educational space which will be used for a decade. The visibility and mobility of a strategy may be low, such as a conference event attended by a private, elite audience, or higher in the case of a public event and very high in the case of on-line resources which can be transmitted digitally. Strategies make use of different socio-historical orientations or indexes through which they align with aspects of a community's past, present or future. For example, some teacher-activists may

\begin{tabular}{llll}
\hline Characteristic & Scale & & \\
\hline Location: & Local & $\leftarrow \rightarrow$ & International \\
Timeframe: & Slow & $\leftarrow \rightarrow$ & Rapid \\
Visibility \& mobility: & Low & $\leftarrow \rightarrow$ & High \\
Socio-historical orientation: & Future & $\leftarrow \rightarrow$ & Past \\
Diversity orientation: & Syncretic & $\leftarrow \rightarrow$ & Purist \\
Participation: & Open participation & $\leftarrow \rightarrow$ & Controlled participation \\
\hline
\end{tabular}

Figure 2: Characteristics of language activism strategies.

choose to focus on concepts related to Zapotec history, such as the pre-colonial base-20 numerical system, while others may focus on neologisms and using language in present or imagined future settings. A related characteristic is the 
orientation towards diversity, whereby some activists will promote linguistic or cultural features perceived to be pure, unitary and authentic, such as writeractivists who strive to avoid all influence of Spanish in their texts. In contrast, other activists promote a more flexible or syncretic (Hill and Hill 1986) understanding of languages and cultures in contact, such as musician-activists who intentionally draw from their multilingual repertoires in their songs. Finally, the dynamics of participation or control can vary from an open, emergent collaboration, to something more tightly controlled and hierarchical. I link this characteristic to the scale Illich established between convivial and manipulative learning environments (Illich 1970), mentioned in section 1.3 above.

Although some of these characteristics may align and impact each other, there is no inherent relationship among them, nor any preferred points on the scales. A strategy may be local, rapid, mobile, purist and with open participation, such as a social media post which corrects or critiques the spelling of another person's post, which then incites further debate for a day or two. A strategy can be international, slow, low-mobility, historically-oriented, and with controlled participation, such as a dictionary of words elicited by a foreign researcher from elder speakers and produced in print version only, which eventually sits in a place of honor in libraries and schools for decades. Maybe the on-line interaction leads someone to feel entitled to write in the minoritized language more often or maybe it does not. Maybe the impressive dictionary inspires a student to learn more about their heritage language - or maybe it does not. A strategy, in short, can be any combination of these characteristics, and any combination can lead to a good strategy, depending on the circumstances. These characteristics are further exemplified throughout the volume (see also chapter 8 for a summary and comparative discussion).

As mentioned above, this framework is intended to describe a range of strategic actions, and does not imply the superiority of strategies with certain targets or characteristics. Strategies do not emerge nor are they carried out in a vacuum; each strategy is embedded in a specific language ecology which shapes and informs the who, what, and how of language activism, and enables or constrains the outcomes (as explored further in chapter 2). Different strategies will thus be more or less possible and desirable depending on the context and the positionality of the activist. For example, high-visibility strategies may appear universally desirable to activists, but low-visibility strategies may in fact be highly effective if carried out by key actors over time. By focusing on language activism strategies within a local context, the Isthmus of Tehuantepec, I hope to draw attention to less-visible, local strategies which I argue deserve more attention and value than they sometimes receive. Future studies of other language activism initiatives could, and hopefully will, extend this framework and repertoire of strategies 
further than I have developed it here. Considering that the social project of linguistic equality must respond to constantly shifting socio-political conditions, I have no doubt that language activists will continue to develop new strategies. We can and we will.

\subsection{Overview of book}

The chapters that follow will illustrate the actions, goals, and characteristics of the repertoire of language activism strategies that is presented in the framework above (Figures 1 and 2). Each chapter focuses on a different social domain which I argue plays an important role in the layered politics of language activism: research; public education; higher education; community-based education; and popular culture. These domains are interrelated in important ways however, as some actors engage in multiple domains (such as education and research), and some strategies involve connecting different domains (such as popular culture and education). These networks of influence and potential support across domains are also crucial to this story and its unfolding outcomes.

Following on from the presentation of language activism strategies in this chapter, chapter 2 shows how language activism is embedded in and influenced by specific language ecologies which are subject to change over time. The sociopolitical history of the Isthmus of Tehuantepec has made this a multilingual region for many centuries, and the shifts in the political, economic, and linguistic ecology provide an important backdrop for language activism in this context. The current linguistic ecology consists of Indigenous languages which arrived at different points in time and European languages which have arrived in subsequent waves as well. I give a brief overview of the linguistic ecology in the pre-colonial, colonial, nation-building, and neoliberal eras, including some of the historical reference points that are drawn upon strategically by language activists today. Cultural and linguistically-oriented activism has a long history in the Isthmus, and continues in a variety of forms, as illustrated in more detail in chapters 3-7.

Multiple domains of scholarship have engaged with minority language advocacy in general, and several scholars have been influential language activists in the Isthmus in particular, including people from the Isthmus and from abroad. Chapter 3 gives an overview of academic engagements with language advocacy and activism, describing scholarly disciplines as communities of practice with varying priorities and concerns. I situate myself as an activist and scholar working across several disciplines, noting that most scholars are members of multiple communities of practice and take a variety of insideroutsider stances in relation to the contexts in which they work. I examine the 
legacy of exploitative research that today's activist scholars attempt to overcome and discuss several ethical and methodological considerations for engaging in language activism. I illustrate the activism strategies taken up by scholars in the Isthmus, in particular a focus on the creation of knowledge and resources, positive representations of Indigenous languages, and supporting connections among people and resources. The colonial history of scholarly activities in the Americas casts a long and influential shadow, and as such, vigilance against exploitation and problematizing hierarchies of knowledge remain crucial. At the same time, the social status of research and the resources which researchers may mobilize can be effective supports to language activism initiatives.

Another social space that enjoys high social status is schooling. Public school communities of practice have immense impact on language socialization. The role of schooling in linguistic equality is explored in chapter 4, including different approaches to language diversity in education. I describe language use in public schooling in the Isthmus and illustrate how Zapotec is largely excluded. I then highlight several groups of teachers who engage in language activism through strategies of connecting students' home life with the school and representing Zapotec as a part of the high-status school environment. Educatoractivists often struggle with the rigidity of the institutions they work in, however, limiting the extent or length of some of their efforts. Additionally, not all stakeholders in school communities share the same imaginary of positive social change; while some parents and educators continue to view Indigenous languages as a problem, educator-activists in favor of Zapotec have both ideological and pedagogical challenges to address.

The gate-keeping and legitimation power of higher education is also crucial in shaping language politics and in some cases in supporting the capacity building of language activists. Chapter 5 analyses a small branch campus of the state university, the Tehuantepec campus of the Faculty of Languages at the Autonomous Benito Juarez University of Oaxaca, which began teaching Isthmus Zapotec for the first time in 2013. In a context where foreign languages have held unquestioned dominance and students at the Faculty who spoke Indigenous languages avoided using them, this represented a significant change. It is also a contrast to the discourses and critiques which young adult speakers of Isthmus Zapotec often experience in their daily lives as multilinguals in this shifting language ecology. I consider the imaginaries of several of the teachers and administrators who have been involved in supporting the program, and the experiences of some participating students. I highlight the significance of higher education in representing Indigenous languages and multilingual identities as legitimate, and in creating the new identity category of Isthmus Zapotec teacher. The slow nature of change within an institutional environment is 
evident, but the impacts are also clearly positive and hopefully sustainable over a longer timeframe.

Literacy and literature have been prominent in Isthmus Zapotec activism at the regional level, and the visibility and popularity of Zapotec writers is an important characteristic of this community. Chapter 6 analyzes the imaginaries and strategies of a community-based literacy workshop, the Camino de la Iguana [Path of the Iguana], which aims to create Zapotec readers and writers. In a social space that they have created, the teachers have the opportunity, and necessity, of imagining what it means to be literate in Diidxazá, and supporting learners of different backgrounds to achieve this goal. The teachers' strategies include promoting an appreciation of Indigenous language and literary heritage, while supporting the multilingual repertoires of emergent speakers and the dialect diversity within the region. Additionally, the political nature of writing is emphasized, with participants encouraged to view themselves as emerging writers who are part of a global community in which Isthmus Zapotec literature is on a par with literature from any country, in any language. The activism strategies within the workshop are characterized by drawing on both historical and contemporary references, as well as both local and international references. The teachers strike a fine balance in their orientation towards diversity, between the inevitable push towards purism in writing practices, and acceptance of language change and variation. The convivial interactions which they prioritize are additionally crucial to the workshop's success.

Chapter 7 describes spaces of cultural production and activism in the Isthmus of Tehuantepec, including the bilingual rap and hip-hop movement, feminist collectives, and on-line activism. Popular culture activists also have a wide scope to imagine new ways of being, and to negotiate what language and identity means to them. Through creative appropriation and reimagining of tradition, as well as engagement with contemporary socio-economic issues, cultural activists strategically bridge the local and global, and the past and the present. The strategies of creating events, representing identities, and connecting people are common among musicians and collectives in the Isthmus. These collectives draw on support and references from outside of the region, but are fundamentally run through voluntary collaboration and local support. They also achieve a high degree of visibility and mobility through their participation in social media and broadcasting. The role of digital spaces in supporting language activism is explored, with attention to initiatives that aim to create resources, as well as those that serve to connect and engage members of the community to discuss issues of language and identity. Here diversity orientations are also present, as popular culture initiatives often spark debates over what is viewed as appropriate or correct linguistic or cultural forms. Popular culture activism occurs in a 
rapid timeframe, and as such may be harder to trace than slower, institutional forms. However, it also has a wider reach in terms of audience and potential impact.

Engaging in different forms of activism or advocacy requires a range of context-sensitive strategies, as illustrated throughout the volume. Chapter 8 summarizes and discusses the actions, goals and characteristics of the language activism strategies framework, drawing on examples from throughout the book. I argue that strategies which occur in local spaces, over a brief span of time and which are not highly visible are still significant in combating inequalities and influencing language politics. I reflect on the challenges of a social constructivist approach to language activism, including shifts in my own strategies over time. Some of the lessons that I have learned from Isthmus Zapotec language activists include accepting the deictic nature of 'language', and the varying theories of change which inform different activism initiatives. Considering activism strategies across initiatives and scales, it is clear that there are no ideal nor one-size-fits-all strategies, but that activists employing a repertoire of adaptable strategies have the potential to resist inequalities and imagine new linguistic futures.

\subsection{Context and conduct of this study}

I was introduced to the Isthmus in 2012 through the generous invitation of Mexican linguist-activist, Gabriela Pérez Báez, and Isthmus Zapotec linguist-writeractivist, Víctor Cata. Gabriela Pérez Báez had been working on documentation and a dictionary of Isthmus Zapotec for over 10 years. She was looking for an applied linguist to assist with education outreach in an ethnobotany documentation project that began as part of the dictionary project, and for which she had received funding from the Smithsonian Institution, where she worked as Curator of Linguistics. Víctor Cata had moved back to his hometown in the Isthmus, Juchitán, a few years before, where he was pursuing his writing and teaching of Diidxazá literacy, as well as collaborating in research projects with scholars like Gabriela. Prior to returning to the Isthmus he had spent two decades in Mexico City, first earning a BA in History and a MA in Amerindian Linguistics, as well as working in the library of the National Anthropological Museum for 10 years. Both of these colleagues were (and are) eager to encourage scholarship on language in the Isthmus, noting that the current legal climate has created opportunities for changing the discriminatory norms surrounding Indigenous languages. Both Víctor and Gabriela approach Indigenous language revitalization and reclamation with passion, transdisciplinary partnerships, and a crucial dose of humor; 
the opportunity to work with and learn from them was far too good to pass up. I was especially interested in the convergence of different actors (linguists, educators, writers) around language issues and the historic multilingualism present in the Isthmus. After a month of pilot research in the Isthmus (April 2013), I returned to live in Juchitán from the beginning of August 2013 through the end of November 2014, and later lived in the state capitol of Oaxaca City from MarchJuly 2015, making regular visits to the Isthmus. I returned for shorter visits to the Isthmus in January 2016, October 2016, April-May 2017, and January 2018. The data that I present here was collected during this timeframe, with some additional on-line data collected in 2018, 2019, and 2020.

With the goal of mapping who was engaged in promoting or teaching Isthmus Zapotec across the region and what they were doing, I visited numerous education and cultural centers, as well as attending civic and cultural events such as poetry readings and hip-hop performances. Wherever possible I followed up to conduct interviews with key individuals. In addition to shorter visits to a variety of sites across the region, I spent extended time as a participant observer in three sites in particular: a community-based literacy initiative (the Camino de la Iguana, see chapter 6); a university campus (the Tehuantepec branch of the Faculty of Languages of the Autonomous Beníto Juárez University of Oaxaca, see chapter 5); and the collaborative outreach workshops which emerged out of Gabriela Pérez Báez's ethnobotany project with community members and researchers (see chapters 3 and 8). As a participant observer in these sites, I was regularly present during Zapotec classes, casual conversations before and after class, and in social interactions with participants. When approved by participants, I conducted audio recordings and took pictures. I also conducted audio-recorded interviews with participants in these sites, in most cases after getting to know them as a co-participant over time. I made field notes while observing, and often after coming home.

I am a settler European-American, and therefor a physical and cultural outsider in the Isthmus. Tourism remains rare there and the only notable white residents during the time of my residence were (primarily Spanish) men locally called eolicos, after the parques eolicos, or wind farm developments where they work. When I first arrived in spring of 2013 there had recently been a fight between some Juchitecos, Juchitán residents, and some eolicos, and a few people advised me to be cautious, in case I was mistaken for a wind farm worker, or more probably, one of their wives. I was occasionally asked if my work was related to the eolicos, but when I then said that I was a researcher interested in language and education, this explanation was always accepted positively or at least neutrally. I often came across people who had had contact with a linguist or researcher in the past due to the residence of (primarily female, American) 
scholars, including missionary-linguist Velma Pickett, and more recently anthropologists Anya Royce, Deborah Augsburger, and Melanie McComsey who had conducted long-term ethnographic research and established close personal ties in Juchitán (Royce 1975; 2011; Augsburger 2004; McComsey 2015). That another American would arrive with an interest in language seemed to be a source of pride, and generally not a surprise.

I conducted my research primarily in Spanish, while continuing to learn Diidxazá and use it frequently in observations and to a more limited degree in conversations. I attempted to adopt a neutral stance with regard to Diidxazá practices in my conversations and interviews (i.e. not taking a stance on standardization, child rearing, etc.). From the beginning, however, I was associated with well-known pro-Diidxazá activists such as Víctor Cata, and people would often associate my work with efforts to rescatar, rescue or recuperate the language, even though I avoided describing my work with these terms. As I began to collaborate in several programs, this identification increased. What people knew about me influenced my subsequent interactions and interviews, and I was frequently told primarily positive comments about Diidxazá use, which were not always reflected in my observations of the social practices of the commenter. Unable to invent a neutral identity, I accepted that my identity created a bias through which I was often told what people thought they should say to an outsider who likes the local language, which is interesting in its own right. Fortunately, the extended nature of my study also allowed for closer acquaintances leading to more candid discussions, as well as observation of everyday communicative practices.

Over time I developed an insider-outsider identity in the three focal contexts mentioned above, eventually participating in lesson and curriculum planning, coorganizing educational events, and speaking at public outreach functions. This insider-outsider status was illustrated in a conversation with several friends and collaborators where I was asked if I preferred to be called huada Haley, a fairly neutral Zapotec word for foreign women, or Teca Haley, a female resident of Juchitán. It seemed that both were acceptable labels to describe me, and I said either one would be fine with me. On another occasion in a group conversation when a visiting Mexican researcher made a negative comment about foreign researchers (not directed at me, although I was present), a teacher whose classes I had been observing quickly excluded me from the comment, saying to the group 'Haley isn't a foreigner, she's a Teca'. Although I remained visibly, audibly, and behaviorally distinct from most of the people around me, I almost always felt that people reacted positively to my presence and to my interest in Diidxazá. 
The generous welcome and kindness of Istmeños aside however, my position as a relative newcomer to the Isthmus inevitably had an influence on what I was able to observe and understand, and on my interpretations of this context. I cannot offer an objective account of language activism in the Isthmus (and I do not believe an objective account is possible); instead I have endeavored to offer a multi-perspectival account, and to draw attention to some of the ways that my own understandings have changed over time through my engagement with language activists in the Isthmus. I discussed my observations with stakeholders throughout the study, getting formal and informal feedback on my ideas and perspectives, and using this feedback to shape the questions I have asked, the ways I have engaged, and how I am presenting the stories here. For example, I was initially interested in spoken communication and not particularly interested in literacy practices, but observations and interviews showed me the clear status of Isthmus Zapotec writing and writers, and led me to consider its significance within the language ecology to a greater degree.

The corpus of notes, interviews, photos, and documents I collected in various sites has been compiled and analysed through rounds of thematic coding, open coding, and memo-writing with the help of the qualitative analysis software Atlas.ti. Throughout this book I draw on data from interviews, field notes, photographs and documents to illustrate my analyses and interpretations (see appendix B for transcription and citation conventions). The specific interviews and field notes that I cite to support discussion or generalizations in the text are representative of things that I heard or observed multiple times. I attempt to relate both the general trends that I observed in relation to language activism in the Isthmus of Tehuantepec, and some of the individual stories of the people who make up this dynamic language ecology. It has been a privilege to observe and learn from language activists in the Isthmus, and to be able to share what I have learned as best I can here and elsewhere. I am all too aware that the trends and stories that I share here are but a glimpse of a much more complex reality, containing many more people and stories than I am able to do justice to. I believe that a glimpse can still be enlightening, however, and I hope that others will find inspiration in the stories in the following chapters, as I have done. 